\title{
Identifying and characterizing the effects of calendar and environmental conditions on pediatric admissions in Shanghai
}

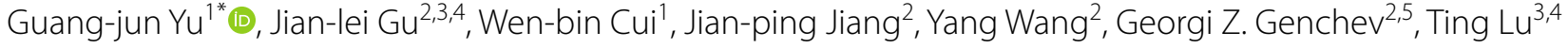 \\ and Hui Lu $2,3,4,6$
}

*Correspondence:

yu_guangjun@hotmail.com

${ }^{1}$ Department of Children's

Healthcare, Shanghai

Children's Hospital, Shanghai

Jiao Tong University, 355

Luding Road, Putuo District,

Shanghai 200062, China

Full list of author information

is available at the end of the

article

\begin{abstract}
Background: Global environmental pollution caused by human activities has become a threat to public health. Children are especially susceptible to adverse environmental conditions owing to their unique physiological and behavioral characteristics. A number of studies have demonstrated associations between the incidence of some childhood diseases and adverse environmental conditions. Shanghai is the largest and most important economic center in China. After rapid population expansion in recent decades, the shortage of pediatric medical resources is becoming a serious public health problem. This study aimed to identify and characterize the social and environmental effect of adverse environmental conditions on overall pediatric admissions at hospitals in Shanghai, China.
\end{abstract}

Methods: This was a multi-center study spanning from January, 2013 to November, 2014. Daily pediatric admission data ( 12,000 overall pediatric admissions/day) of three tertiary pediatric hospitals were collected from the large-scale health information exchange network of Shanghai. We linked the admission data with local environmental data. A seasonal decomposition method was applied to a time-trend analysis of the admission data; a generalized additive model was applied to model the association between environmental measurements and admissions data.

Results: Admissions to outpatient and emergency departments were highly influenced by calendar factors; however, these same factors showed opposite effects on different clinical departments. The effect of nitrogen dioxide was a $0.27 \%$ increase $(95 \%$ confidence interval (Cl) $0.23 \%$ to $0.32 \%$ ) in outpatient admissions and $0.78 \%(95 \% \mathrm{Cl}$ $0.68 \%$ to $0.88 \%$ ) increase in emergency admissions. Concentrations of fine particles $\leq 2.5$ micrometers in diameter (PM2.5) and carbon monoxide (CO) showed multi-faceted effects on pediatric admissions. PM2.5 and CO concentrations were significantly associated with decreased current-day outpatient admissions but also significantly associated with increased current-day emergency admissions at all three hospitals.

Conclusions: Based on the health information exchange network of Shanghai, we conducted a large-scale, multi-center retrospective study of the association between adverse environmental conditions and pediatric admissions. Our study contributes to environmental health research in children and may guide decision-making regarding pediatric resource planning and policies. 
Keywords: Pediatric care, Retrospective analysis, Hospital admissions, Generalized additive model, Environment, Shanghai, China

\section{Introduction}

It is well known that a turbulently changing or polluted environment can directly create health risks and induce illnesses. Over the past decade, a large number of studies have been conducted in this regard, and this topic is growing in popularity with respect to assessing various diseases [1-6]. For instance, in 2008, Bell and colleagues studied the short-term effects of PM2.5 (fine particles 2.5 micrometers or less in diameters) on hospitalization risk for cardiovascular and respiratory illnesses in the elderly population across 202 United States counties, from 1999 to 2005. The authors found about a 1.05\% and $1.49 \%$ increase in hospitalizations per $10 \mu \mathrm{g} / \mathrm{m}^{3}$ increase in current-day PM2.5 for respiratory and cardiovascular diseases, respectively [7]. However, there are still relatively few studies on the association between adverse environmental conditions and childhood illnesses.

"Children are not little adults" [8]. Infancy and childhood are critical periods for the development and maturation of important organs, such as those of the respiratory system, and the immune system. Children are much more susceptible to environmental hazards than adults $[9,10]$. Studies of adverse environmental conditions in relation to causing or exacerbating childhood illnesses are increasingly being emphasized [8, 1113]. Such childhood illnesses can result in pediatric hospital admissions [14, 15], school absences, dysfunction of the respiratory or immune systems, bronchitis and chronic cough, and increased infant mortality [11]. Although some of these studies have not reached a clear conclusion, it has been recognized that adverse environmental conditions can have a serious impact on a child's health. Most previous studies have attempted to find the association between adverse environmental conditions and a single childhood disease. It is worth conducting comprehensive studies exploring the time trends and associations between adverse environmental conditions and overall pediatric hospital admissions.

Shanghai is the largest city in China, with over 24 million permanent residents and 9 million migrant residents. About 1.98 million residents of the city are under 14 years of age. Pediatric medical resources have become the most overburdened component in this urban system. According to reports, the average bed-occupancy rate in all four tertiary pediatric hospitals of Shanghai has consistently remained at 100\% [16].

On September 2010, the first and largest Chinese Health Information Exchange (HIE) network was established in Shanghai. As of 2016, the system includes all of Shanghai's 38 tertiary hospitals, plus 6 district hospitals, and 40 community health centers, with coverage for 39 million patients. The HIE network currently provides a rich source of patient information including diagnostics history, medication history, laboratory results, radiology images and reports, and clinical notes.

Based on daily admission data collected from three tertiary pediatric hospitals of the Shanghai HIE network, we aimed to link pediatric admission data to local environmental data. The principal objective of this study was to identify and characterize the effect of short-term adverse environmental conditions on trends in pediatric admissions, using a generalized additive model (GAM). Insights into these effects for a hospital or 
Table 1 Summary statistics of daily hospital admission and local environmental measurements, Shanghai (January 2013-November 2014)

\begin{tabular}{|c|c|c|c|c|c|}
\hline & & Mean & Median & Maximum & SD \\
\hline \multicolumn{6}{|c|}{ Daily hospital admission (visit number/day) } \\
\hline \multirow[t]{2}{*}{ Hospital A } & Outpatient & 5020 & 5248 & 7291 & 1233.6 \\
\hline & Emergency & 677 & 681 & 1011 & 88.6 \\
\hline \multirow[t]{2}{*}{ Hospital C } & Outpatient & 3074 & 3282 & 4598 & 778.2 \\
\hline & Emergency & 711 & 707 & 1155 & 146.3 \\
\hline \multirow[t]{2}{*}{ Hospital D } & Outpatient & 2072 & 2291 & 3375 & 745.9 \\
\hline & Emergency & 903 & 823 & 1947 & 297.3 \\
\hline \multirow[t]{2}{*}{ Total } & Outpatient & 10,170 & 10,730 & 15,010 & 2553 \\
\hline & Emergency & 2292 & 2259 & 3964 & 447 \\
\hline \multicolumn{6}{|c|}{ Weather measurements } \\
\hline \multicolumn{2}{|c|}{ Temperature $\left({ }^{\circ} \mathrm{C}\right)$} & 17.85 & 18.73 & 35.02 & 8.7 \\
\hline \multicolumn{2}{|l|}{ TDIF24H $\left({ }^{\circ} \mathrm{C}\right)$} & 5.6 & 6.21 & 20.6 & 3.33 \\
\hline \multicolumn{2}{|l|}{ MTD48H $\left({ }^{\circ} \mathrm{C}\right)$} & 1.58 & 1.21 & 14.64 & 1.44 \\
\hline \multicolumn{2}{|l|}{ PM2.5 $\left(\mu \mathrm{g} / \mathrm{m}^{3}\right)$} & 56.17 & 44 & 447 & 41.5 \\
\hline \multicolumn{2}{|l|}{ PM10 ( $\left.\mu \mathrm{g} / \mathrm{m}^{3}\right)$} & 74.91 & 60 & 467 & 49.4 \\
\hline \multicolumn{2}{|l|}{$\mathrm{SO}_{2}\left(\mu \mathrm{g} / \mathrm{m}^{3}\right)$} & 19.96 & 15 & 103 & 14.2 \\
\hline \multicolumn{2}{|l|}{$\mathrm{NO}_{2}\left(\mu \mathrm{g} / \mathrm{m}^{3}\right)$} & 45.74 & 41 & 136 & 20.8 \\
\hline \multicolumn{2}{|l|}{$\mathrm{CO}\left(\mathrm{mg} / \mathrm{m}^{3}\right)$} & 0.7958 & 0.7100 & 3.023 & 0.3 \\
\hline \multicolumn{2}{|l|}{$\mathrm{O}_{3}\left(\mu \mathrm{g} / \mathrm{m}^{3}\right)$} & 103.8 & 98 & 302 & 41.9 \\
\hline \multicolumn{2}{|l|}{$\mathrm{PRCP}(\mathrm{mm})$} & 3.98 & 0 & 189.5 & 12.0 \\
\hline
\end{tabular}

TDIF24H is the difference of temperature in $24 \mathrm{~h}$

$M T D 48 H$ is the absolute value of mean temperature differences over 2 days

$P R C P$ is the daily precipitation

a particular region could provide a whole picture of pediatric admission trends under adverse environmental conditions impact. Our findings will be of value when allocating and planning pediatric resources and some references for future studies on specific diseases and environmental associations.

\section{Research methodology}

\section{Data sources}

This retrospective study used a daily pediatric hospital admission dataset obtained from the HIE network (Shanghai Hospital Development Center). We did not directly involve any individual participants, and no individual information was collected. To protect sensitive data, we masked the names of these hospitals and used the codes A, C, and D to represent each hospital. Daily local weather measurements were obtained from the Shanghai Environment Monitoring Center (http://www.semc.gov.cn/) and the United States National Oceanic Atmospheric Administration (NOAA, https://www.ncdc.noaa. gov/).

From January 1, 2013 to November 30, 2014, the three pediatric hospitals in Shanghai had a total of $\sim 10,000$ and $\sim 2000$ daily outpatient and emergency admissions, respectively (Table 1). Hospital A accounted for about $50 \%$ of all outpatient admissions, and Hospital D accounted for about $40 \%$ of the total emergency admissions. For outpatient 

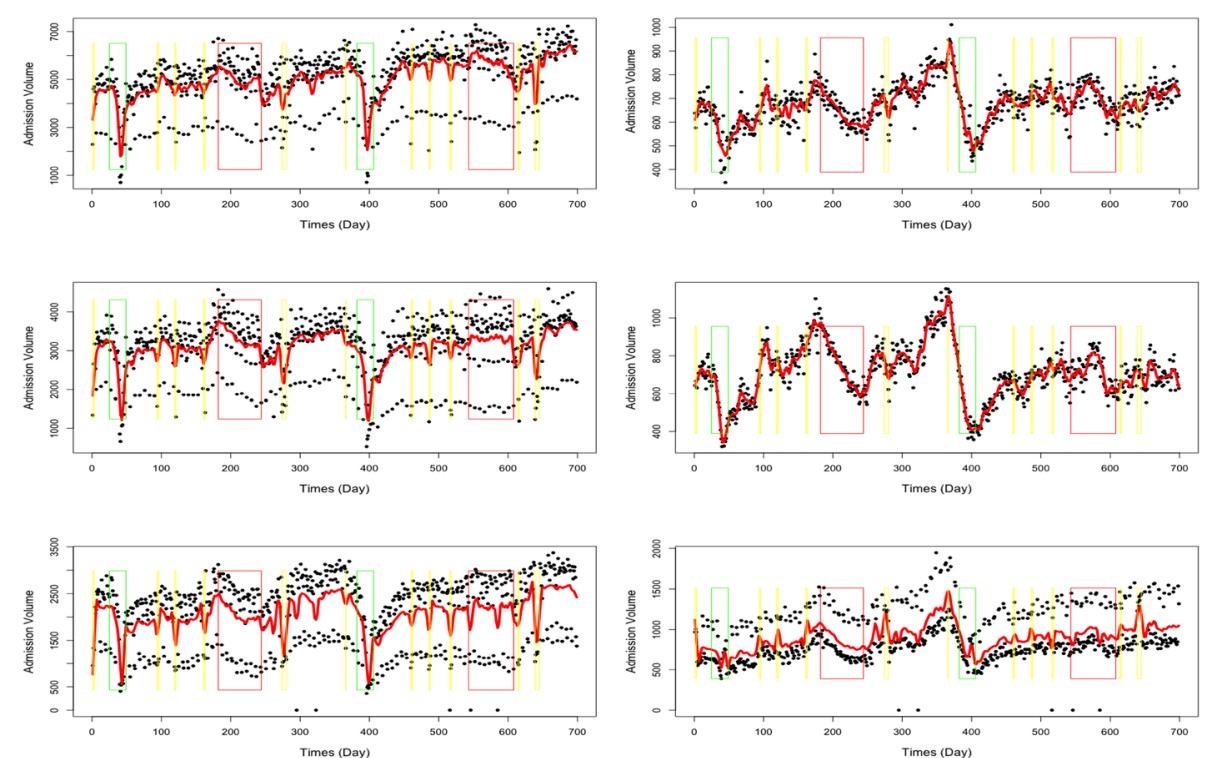

Fig. 1 Time plot of daily admissions from January 1, 2013 to November 30, 2014. Left diagram is outpatient admissions, and the right is emergency admissions; the upper diagram is Hospital A, middle is Hospital C, and lower diagram is Hospital D. Red lines indicate the de-seasonalized trend in hospital admissions. Green and red boxes represent winter and summer school vacations, and yellow boxes are public holidays

and emergency admissions, a similar long-term time trend of admissions was observed for these three hospitals (Fig. 1).

\section{Statistical modeling}

We used a GAM with log-link function to infer the associations between environmental conditions and pediatric admissions. The GAM is a general linear regression approach that incorporates smoothing splines to describe non-linear relationships between the predictor and response variables. The GAM has been widely used in previous studies $[17,18]$.

First, we generated a single-pollutant model and fitted it with each environmental condition. For example, the single-pollutant model with nitrogen dioxide $\left(\mathrm{NO}_{2}\right)$ concentration as the independent variable can be specified as:

$$
\begin{aligned}
\log \mathrm{E}\left(\mathrm{Y}_{\mathrm{t}}\right)= & \beta \mathrm{X}_{\mathrm{t}}+\mathrm{s}(\mathrm{t}, d f=9)+\mathrm{PRCP}+\mathrm{PRCP}_{\text {lag1 }} \\
& + \text { Weekday }+ \text { Month }+ \text { School }+\mathrm{PH}
\end{aligned}
$$

Here, $E\left(Y_{t}\right)$ refers to the expected pediatric admissions on day t; $X_{t}$ indicates the environmental condition $\left(\mathrm{NO}_{2}\right.$ in this case) on day $t$; the regression coefficient $\beta$ represents the log-relative rate of hospital admission count associated with a one-unit increase of the environmental condition.

The $s(t, d f)$ term indicates a penalized splines smoothing function for long-term time trend. Selection of the degrees of freedom of this splines function was based on automatic $d f$ selection of the single-pollutant model as well as a previous study [19]. In this 
study, $9 d f$ for the time trend was selected for all single-pollutant and multi-pollutant regression models.

The environment effect estimates were expressed as excess risk (ER), the exponent of $\beta-1) * 100 \%$, and $95 \%$ confidence intervals $(\mathrm{CI})$. The remaining variables were all control variables, $P R C P$ is a categorical variable representing the amount of precipitation: no rainfall $(0 \mathrm{~mm})$, light rainfall $(0.1-9.9 \mathrm{~mm})$, moderate rainfall (10.0$24.9 \mathrm{~mm})$, heavy rainfall $(25.0-49.9 \mathrm{~mm})$, and extreme rainfall $(\geq 50 \mathrm{~mm})$. Weekday is a categorical variable indicating the day of week; Month is a categorical variable indicating the month of year; School is a categorical variable indicating the summer/ winter vacation; and $P H$ is a categorical variable indicating the public holiday effect.

Next, a multi-pollutant analysis was conducted to estimate regression coefficients and their significance level. The multi-pollutant regression model was specified as:

$$
\begin{aligned}
\log \mathrm{E}\left(\mathrm{Y}_{\mathrm{t}}\right)= & \mathrm{PM} 2.5+\mathrm{PM} 2.5_{\operatorname{lag} 2}+\mathrm{PM} 2.5_{\operatorname{lag} 4 \mathrm{MA}}+\mathrm{SO}_{2}+\mathrm{SO}_{2_{\mathrm{lag} 2}}+\mathrm{SO}_{2_{\mathrm{lag} 4 M A}} \\
& +\mathrm{O}_{3}+\mathrm{O}_{3_{\operatorname{lag} 2}}+\mathrm{O}_{3_{\operatorname{lag} 4 \mathrm{MA}}}+\mathrm{TDIF} \\
& +\mathrm{TDIF} 24 \mathrm{H}_{\mathrm{lag} 1}+\mathrm{TDIF} 24 \mathrm{H}_{\mathrm{lag} 4 \mathrm{MA}}+\mathrm{s}(\mathrm{t}, d f=9) \\
& +\mathrm{PRCP}+\mathrm{PRCP}_{\operatorname{lag} 1}+\text { Weekday }+ \text { School }+ \text { Month }+\mathrm{PH}
\end{aligned}
$$

As the daily concentrations of fossil fuel-related air pollutants are highly correlated, we only included two fossil fuel-related pollutants in the multi-pollutant analysis: PM2.5 and Sulphur dioxide $\left(\mathrm{SO}_{2}\right) . \mathrm{O}_{3}$ is the ground-level ozone concentration, and $T D I F 24 \mathrm{H}$ is the difference of temperature in $24 \mathrm{~h}$.

There is usually a time delay between adverse environmental conditions and an increase in hospital admissions. We examined various lag structures, including both simple single/multi-day lag (for example, PM2.5 lagl is lag 1 day for PM2.5) and multiday cumulative lag structures (for example, $P M 2.5_{\text {lag } 4 M A}$ is a 4-day moving average of $P M 2.5)$. A simple single/multi-day lag structure was used to estimate the lag effect of environmental conditions and a multi-day moving average lag structure was applied to examine the cumulative effect of environmental conditions on pediatric admissions. In our single-pollutant regression model, we tested the 1-day to 6-day simple lag effect and 2-day to 6-day cumulative lag effect, to determine the optimal lag and cumulative structures for the multi-pollutant model; lag2 and lag4MA were selected for $P M 2.5, \mathrm{SO}_{2}$, and $\mathrm{O}_{3}$; lag1 and lag4MA were selected for TDIF24H; and lag1 was selected for PRCP.

The R (https://www.cran.r-project.org/) package " $m g c v$ " was used to build the GAM and the "stats" package was used to perform seasonal decomposition analysis [20].

\section{Results}

The focus of this work was to uncover the environmental effects on pediatric hospital admissions in Shanghai, by using statistical modeling, admission data sourced from three tertiary pediatric hospitals in Shanghai; and meteorological and air quality data. Our results describe the following aspects: the effect of calendar factors, the effect of environmental conditions-regression results for a single and multiple pollutants, as well as ozone, and temperature effects. 


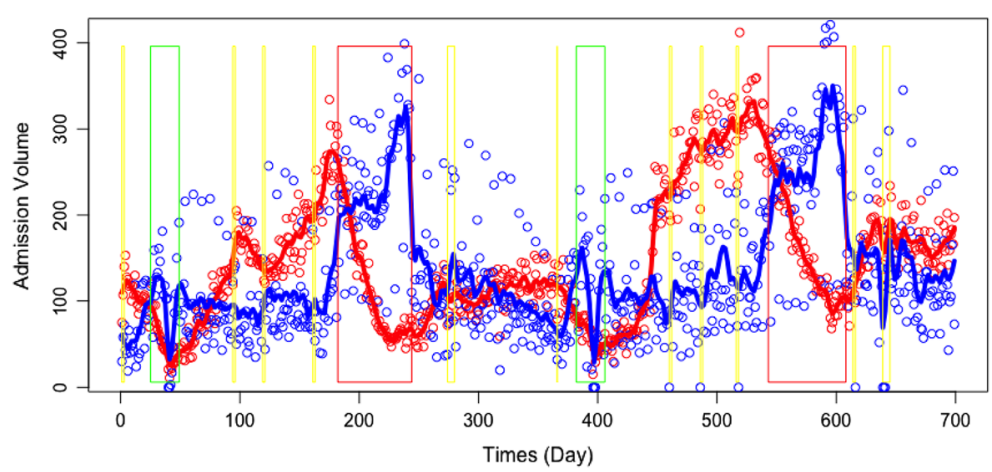

Fig. 2 Comparison of outpatient admissions between the endocrinology and infectious disease departments during 2013-2014. The blue and red lines are de-seasonalized admissions to the endocrinology and infectious disease departments. Green and red boxes represent winter and summer school vacations, and yellow boxes are public holidays

\section{Calendar factors effect on pediatric admissions volume}

The number of outpatient admissions was strongly affected by calendar factors, including the day of week, public holidays, the month, and school term (Figs. 1, 2 and Additional file 1: Figs. S1 and S2). For outpatient departments, Monday was the busiest day, whereas Sunday and public holidays were the busiest days in emergency departments. The lowest number of hospital admissions was observed in the month of February. The calendar effects described above varied slightly among hospitals; however, the number of emergency admissions was relatively more stable than the number of outpatient admissions. Pediatric patient admissions volumes were also strongly affected by school vacations (Fig. 1, Additional file 1: Fig. S3).

In specific pediatric department (Fig. 2), for example, the infectious disease department, the number of admissions increased steadily, when the new school term began; and this increase in admissions volume reached its peak at the end of the school term. However, the number of admissions to infectious disease departments decreased significantly during the summer vacation. In contrast, the number of admissions to endocrinology departments remained at a relatively low level throughout the year, but then significantly increased during the summer vacation.

\section{Effect of environmental conditions on pediatric hospital admissions}

In this segment we focus on exploring the environmental condition effect on pediatric hospital usage. The environmental conditions in Shanghai are considered as well as the effects of single pollutants, temperature, ozone, and multiple pollutants.

\section{Environmental conditions in Shanghai}

During our research period, the mean daily temperature, temperature difference within $24 \mathrm{~h}$, and absolute mean temperature difference within $48 \mathrm{~h}$ were $17.85{ }^{\circ} \mathrm{C}, 5.6^{\circ} \mathrm{C}$, and $1.58{ }^{\circ} \mathrm{C}$, respectively. Air quality in Shanghai varies through the year, and is sometimes poor, especially in winter. The mean daily concentrations of PM2.5, PM10, $\mathrm{SO}_{2}, \mathrm{NO}_{2}$, $\mathrm{CO}$, and $\mathrm{O}_{3}$ were $56.17 \mu \mathrm{g} / \mathrm{m}^{3}, 74.91 \mu \mathrm{g} / \mathrm{m}^{3}, 19.96 \mu \mathrm{g} / \mathrm{m}^{3}, 45.74 \mu \mathrm{g} / \mathrm{m}^{3}, 0.80 \mathrm{mg} / \mathrm{m}^{3}$, and $103.8 \mu \mathrm{g} / \mathrm{m}^{3}$, respectively. For about $30 \%$ of the days in our research period, the daily 


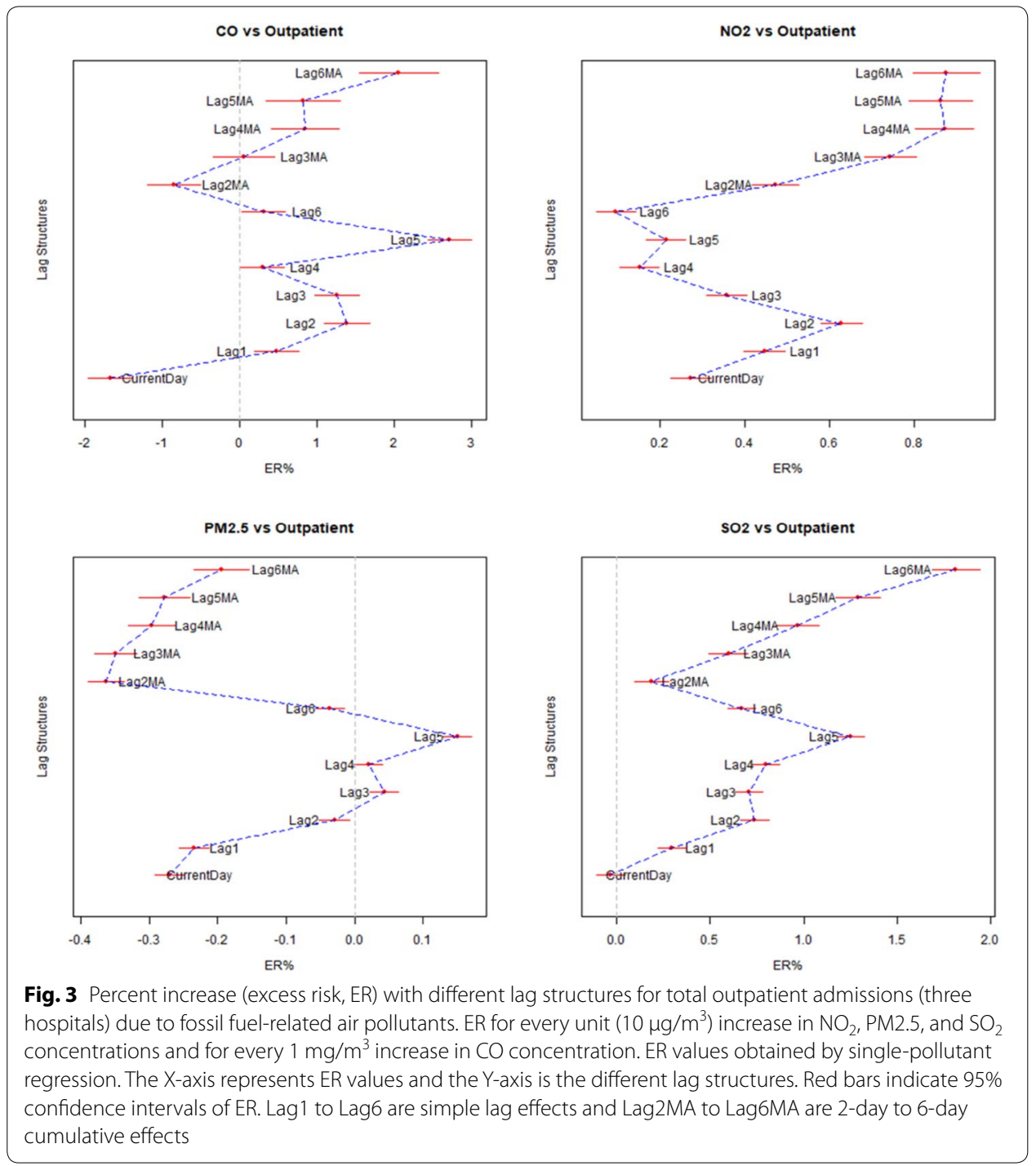

concentration of $\mathrm{SO}_{2}$ failed to meet the World Health Organization (WHO) standard limits $\left(20 \mu \mathrm{g} / \mathrm{m}^{3}\right)$.

Fossil fuel-related air pollutants, including PM10, PM2.5, CO, $\mathrm{SO}_{2}$, and $\mathrm{NO}_{2}$, were strongly inter-correlated (Additional file 2: Table S1); the Pearson coefficients among these pollution factors were all higher than 0.7 . The daily concentration of ground-level $\mathrm{O}_{3}$, which is created by chemical reactions between air pollutants and oxygen in the presence of strong sunlight, was not strongly correlated with any fossil fuel-related air pollutants.

\section{Regression results for single pollutants}

Effect of fossil fuel-related air pollutants on pediatric admissions

Environmental effects on pediatric admissions and their lag structures were estimated using a GAM model and adjusted according to calendar factors and rainfall amount. Fossil fuel-related air pollutants appeared to produce multi-faceted effects 
on pediatric admissions to pediatric outpatient departments (Fig. 3). The currentday concentration of $\mathrm{NO}_{2}$ was positively related to the number of outpatient admissions. For every unit $\left(10 \mu \mathrm{g} / \mathrm{m}^{3}\right)$ increase in $\mathrm{NO}_{2}$ concentration, the total number of outpatient admissions increased $0.27 \%$ (95\% CI $0.23 \%$ to $0.32 \%)$. However, no significant effect was observed for the current-day concentration of $\mathrm{SO}_{2}$. Surprisingly, the current-day concentrations of PM2.5 and $\mathrm{CO}$ were associated with a significantly reduced number of outpatient admissions. For every unit increase in PM2.5 and CO concentration $\left(10 \mu \mathrm{g} / \mathrm{m}^{3}\right.$ and $1 \mathrm{mg} / \mathrm{m}^{3}$, respectively), the total number of outpatient admissions decreased $0.27 \%$ (95\% CI $0.25 \%$ to $0.29 \%$ ) and $1.7 \%$ (95\% CI $1.38 \%$ to $1.96 \%)$, respectively. The lag and cumulative effects of these fuel consumption-related environmental conditions on outpatient admissions were remarkably significant for the simple lag-2 day and lag- 4 day moving average. For the simple lag- 2 days of $\mathrm{CO}$, $\mathrm{NO}_{2}$, and $\mathrm{SO}_{2}$ concentrations, the ER increased to $1.38 \%$ (95\% CI $1.09 \%$ to $1.68 \%$ ), $0.63 \%$ ( $95 \%$ CI $0.58 \%$ to $0.68 \%$ ), and $0.74 \%$ ( $95 \%$ CI $0.66 \%$ to $0.81 \%$ ), respectively. For the lag-4 day cumulative effects of $\mathrm{CO}, \mathrm{NO}_{2}$, and $\mathrm{SO}_{2}$ concentrations, the ER was $0.84 \%$ ( $95 \%$ CI $0.41 \%$ to $1.29 \%$ ), $0.87 \%$ ( $95 \%$ CI $0.80 \%$ to $0.94 \%$ ), and $0.97 \%$ (95\% CI $0.86 \%$ to $1.08 \%)$, respectively.

For pediatric emergency departments (Fig. 4), fossil fuel-related air pollutants showed clearer positive associations with pediatric admissions. For every unit $\left(10 \mu \mathrm{g} / \mathrm{m}^{3}\right.$ for PM2.5, $\mathrm{NO}_{2}$, and $\mathrm{SO}_{2}$ and $1 \mathrm{mg} / \mathrm{m}^{3}$ for $\mathrm{CO}$ ) increase, the total number of emergency admissions increased $0.17 \%$ (95\% CI $0.13 \%$ to $0.21 \%$ ), $0.78 \%$ (95\% CI $0.68 \%$ to $0.88 \%$ ), $1.99 \%$ ( $95 \%$ CI $1.40 \%$ to $2.59 \%$ ), and $0.84 \%$ (95\% CI $0.68 \%$ to $0.99 \%$ ) for current-day concentration of $\mathrm{PM} 2.5, \mathrm{NO}_{2}, \mathrm{CO}$, and $\mathrm{SO}_{2}$, respectively. All fossil fuel-related air pollutants showed strong positive cumulative effects on the number of emergency admissions. For the lag-4 day moving average cumulative effects of PM2.5, $\mathrm{NO}_{2}, \mathrm{CO}$, and $\mathrm{SO}_{2}$, the ER increased to $0.39 \%$ (95\% CI $0.32 \%$ to $0.45 \%$ ), $1.86 \%$ (95\% CI $1.72 \%$ to $2.01 \%$ ), $6.26 \%$ (95\% CI $5.32 \%$ to $7.21 \%$ ), and $2.90 \%$ (95\% CI $2.67 \%$ to $3.14 \%$ ), respectively. Only $\mathrm{SO}_{2}$ showed a clear positive lag effect on emergency admissions. For simple lag-2 days, the ER of $\mathrm{SO}_{2}$ increased to $1.55 \%$ (95\% CI $1.40 \%$ to $1.70 \%$ ).

\section{Effect of temperature changes on pediatric admissions}

We examined two types of short-term temperature changes: temperature differences in $24 \mathrm{~h}$ (TDIF24H; the maximum temperature minus the minimum temperature in 1 day) and the absolute value of mean temperature differences over 2 days (MTD48H) (Fig. 5). Short-term temperature change showed significant and positive associations with outpatient and emergency admissions, and TDIF24H showed a clearer positive association than the association showed by MTD48H. For every unit $\left(1{ }^{\circ} \mathrm{C}\right)$ increase in the currentday TDIF24H, the total number of outpatient and emergency admissions increased $0.06 \%$ ( $95 \%$ CI $0.04 \%$ to $0.09 \%$ ) and $0.64 \%$ (95\% CI $0.59 \%$ to $0.70 \%$ ), respectively. TDIF24H also showed clear lag and cumulative effects on the number of outpatient admissions. For the simple lag-1-day effect of TDIF24H, ER increased to $0.23 \%$ (95\% CI $0.21 \%$ to $0.26 \%$ ) and $0.52 \%$ ( $95 \%$ CI $0.47 \%$ to $0.58 \%$ ) for outpatient and emergency admissions, respectively. For lag- 4 day cumulative effects of TDIF24H, the ER increased to $0.43 \%$ (95\% CI $0.39 \%$ to $0.47 \%$ ) and $1.15 \%$ (95\% CI $1.06 \%$ to $1.24 \%$ ) for outpatient and emergency admissions, respectively. 

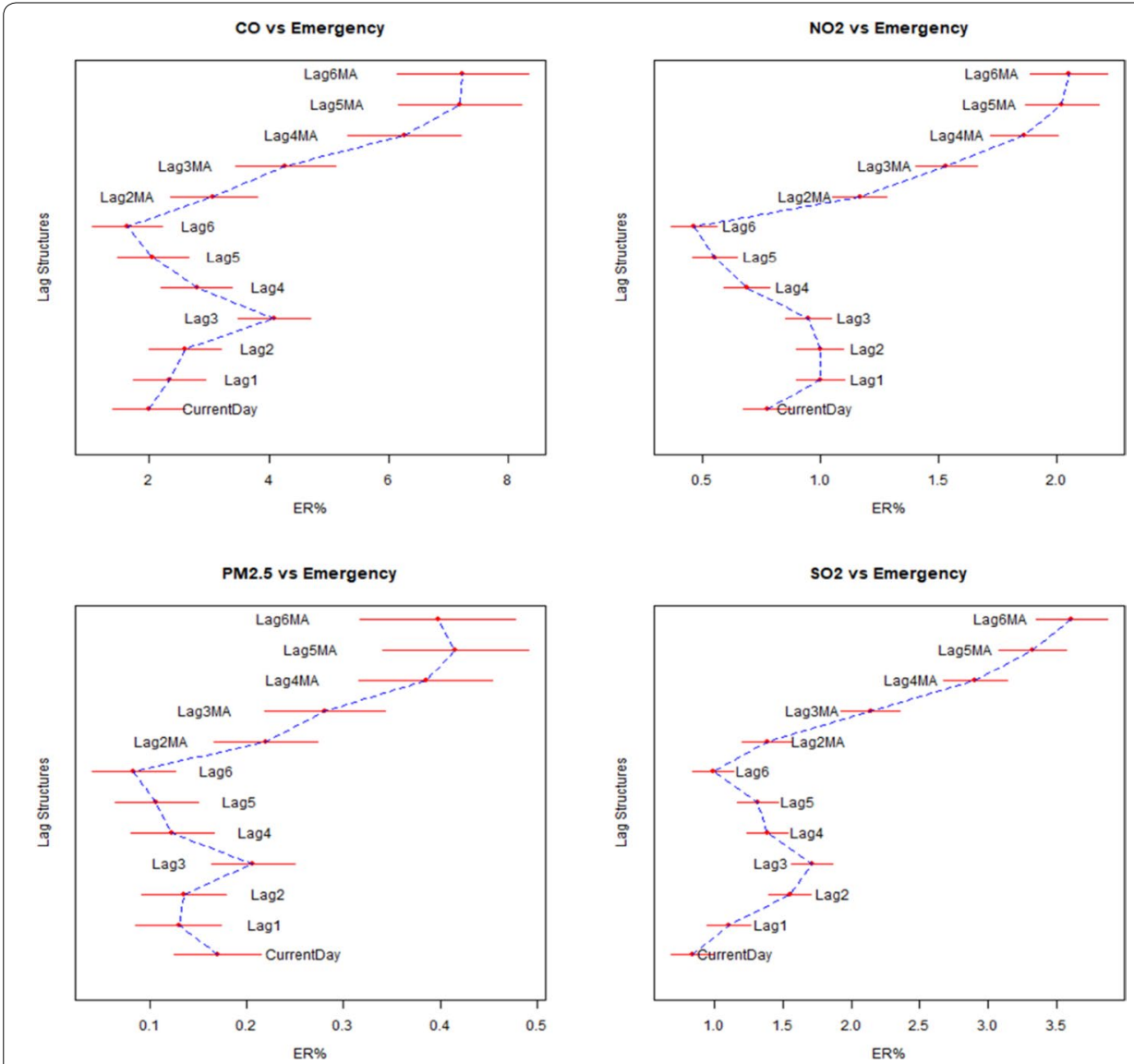

Fig. 4 Percent increase (excess risk, ER) with different lag structures for total emergency admissions (three hospitals) owing to fossil fuel-related air pollutants. ER for each unit $\left(10 \mu \mathrm{g} / \mathrm{m}^{3}\right)$ increase in $\mathrm{NO}_{2}$, $\mathrm{PM} 2.5$, and $\mathrm{SO}_{2}$ concentrations and for each $1 \mathrm{mg} / \mathrm{m}^{3}$ increase in $\mathrm{CO}$ concentration. ER values obtained by single-pollutant regression. The $X$-axis represents ER values, and the $Y$-axis is the different lag structures. Red bars indicate 95\% confidence intervals of ER. Lag1 to Lag6 are simple lag effects and Lag2MA to Lag6MA are 2-day to 6-day cumulative effects

\section{Effect of ground-level ozone on pediatric admissions}

$\mathrm{O}_{3}$ production is associated with hot, dry weather; in a sense, the $\mathrm{O}_{3}$ concentration is a good weather indicator. The ground-level $\mathrm{O}_{3}$ effects are displayed in Fig. 6. The currentday $\mathrm{O}_{3}$ concentration had strong negative effects on outpatient admissions but strong positive effects on emergency admissions. For every unit $\left(10 \mu \mathrm{g} / \mathrm{m}^{3}\right)$ increase in currentday $\mathrm{O}_{3}$ concentration, the ER decreased $0.06 \%$ (95\% CI $0.04 \%$ to $0.09 \%$ ) for outpatient admissions and increased $0.42 \%$ (95\% CI $0.37 \%$ to $0.47 \%$ ) for emergency admissions. Interestingly, as the multi-day moving average increased, the cumulative effects on outpatient and emergency admissions decreased.

Multi-pollutant regression results - effect of environmental conditions on pediatric admissions For outpatient departments, PM2.5 concentration was significantly and negatively associated with pediatric admissions (Table 2). For each one-unit increase of the current-day and lag-4 moving average of PM2.5 concentration, the ER value was $-0.31 \%$ (95\% CI 


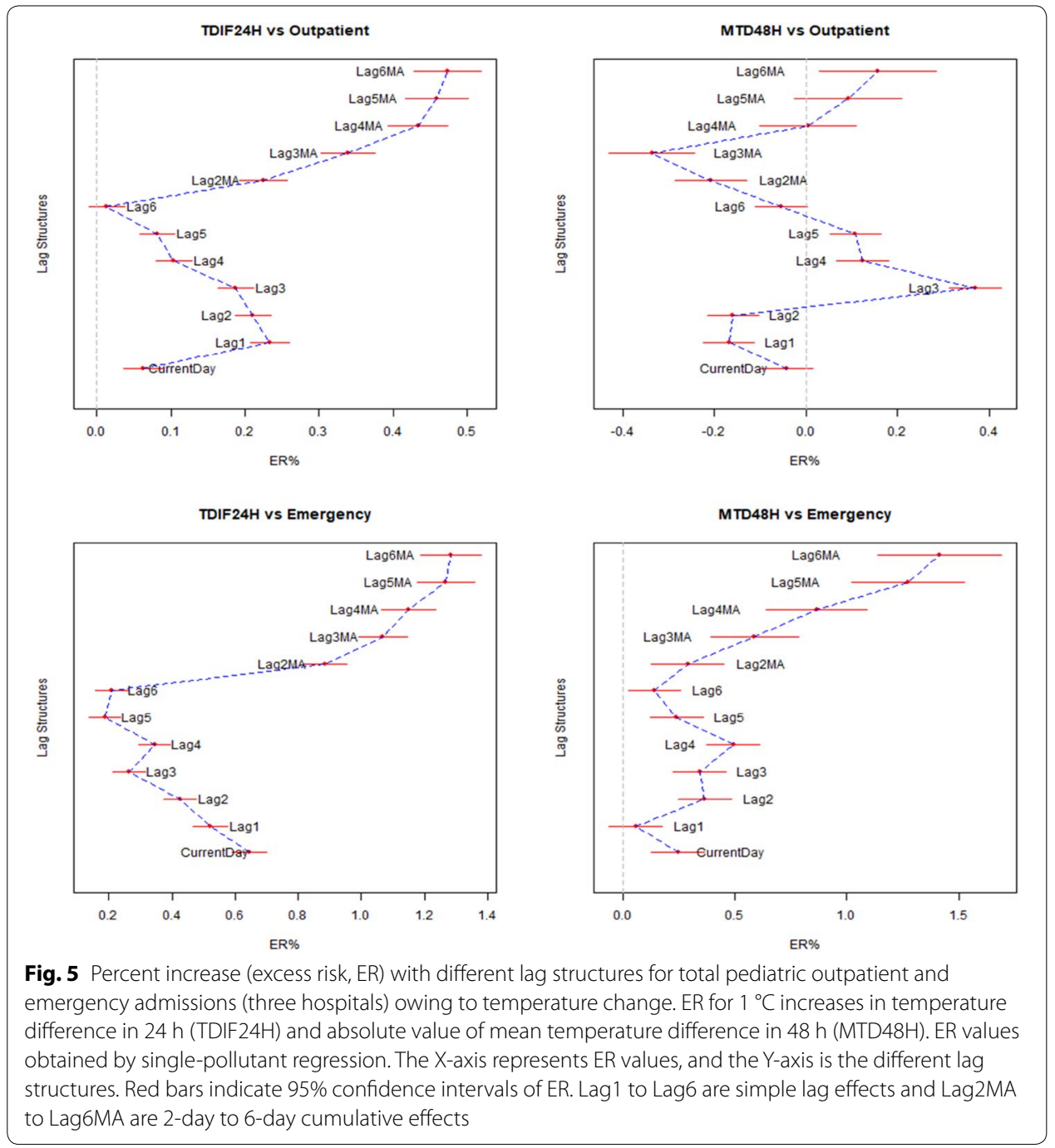

$-0.36 \%$ to $-0.25 \%)$ and $-0.65 \%$ ( $95 \% \mathrm{CI}-0.77 \%$ to $-0.54 \%)$, respectively. However, the $\mathrm{SO}_{2}$ concentration was strongly and positively associated with outpatient admissions; for each one-unit increase of the current-day and lag-4 moving average of $\mathrm{SO}_{2}$ concentration, the ER value was $0.48 \%$ (95\% CI 0.30 to $0.66 \%$ ) and $1.66 \%$ (95\% CI $1.26 \%$ to $2.07 \%$ ), respectively. The simple lag- 2 days of $\mathrm{O}_{3}$ concentration had a significant negative effect on the number of patient admissions, with $\mathrm{ER}$ for $\mathrm{O}_{3_{\operatorname{lag} 2}}$ of $-0.13 \%$ (95\% CI $-0.17 \%$ to $-0.08 \%)$. In addition, the current-day TDIF $24 \mathrm{H}$ was significantly associated with decreased outpatient admissions (ER $-0.17 \%, 95 \% \mathrm{CI}-0.21 \%$ to $-0.13 \%$ ), but the lag-4 moving average of TDIF24H was significantly associated with increased outpatient admissions (ER $0.67 \%$, 95\% CI $0.59 \%$ to $0.75 \%$ ).

For emergency departments, PM2.5 also showed a negative association with admissions (Fig. 2) For current-day and simple lag-2 day of PM2.5 concentration, the ER was $-0.15 \%(95 \% \mathrm{CI}-0.26 \%$ to $-0.04 \%)$ and $-0.30 \%(95 \% \mathrm{CI}-0.44 \%$ to $-0.16 \%)$, respectively. Unlike outpatient admissions, the PM2.5 concentration had a significant positive association with emergency admissions, with ER value of $0.24 \%$ (95\% CI $0.00 \%$ to $0.48 \%$ ). 


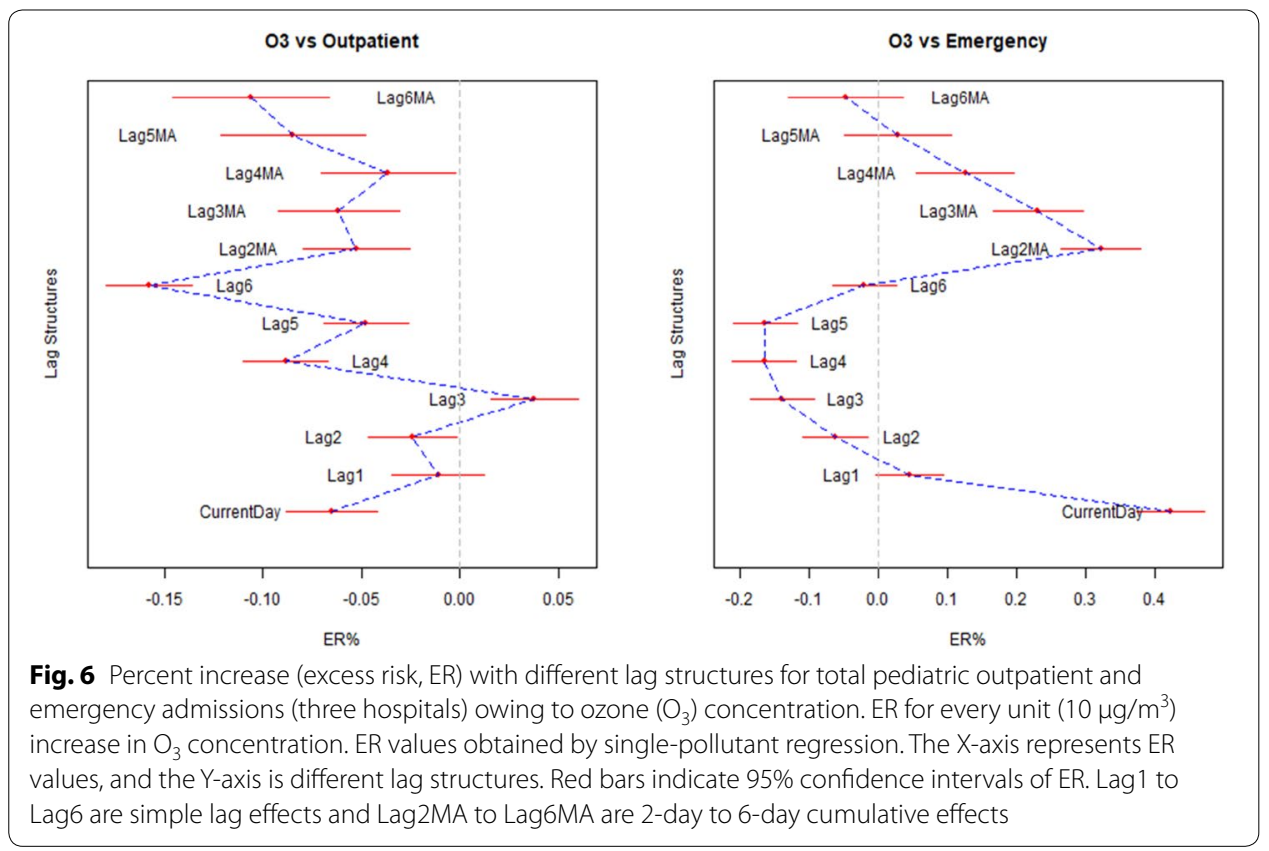

Table 2 Multi-pollutant linear regression for pediatric outpatient admissions

\begin{tabular}{|c|c|c|c|c|c|c|}
\hline & Outpatie & & & Emerge & & \\
\hline & $\operatorname{ER}(\%)^{a}$ & $95 \% \mathrm{Cl}$ & P-value & ER (\%) & $95 \% \mathrm{Cl}$ & P-value \\
\hline PM2.5 & $-0.31^{*}$ & {$[-0.36,-0.25]$} & 0.0000 & $-0.15^{*}$ & {$[-0.26,-0.04]$} & 0.0074 \\
\hline PM2.5_lag2 & $0.09^{*}$ & {$[0.02,0.15]$} & 0.0111 & $-0.30^{*}$ & {$[-0.44,-0.16]$} & 0.0000 \\
\hline PM2.5_lag4MA & $-0.65^{*}$ & {$[-0.77,-0.54]$} & 0.0000 & $0.24^{*}$ & {$[0.00,0.48]$} & 0.0493 \\
\hline $\mathrm{SO}_{2}$ & $0.48^{*}$ & {$[0.30,0.66]$} & 0.0000 & -0.18 & {$[-0.55,0.19]$} & 0.3364 \\
\hline $\mathrm{SO}_{2 \operatorname{lag} 2}$ & -0.14 & {$[-0.37,0.09]$} & 0.2351 & $0.74^{*}$ & {$[0.29,1.20]$} & 0.0015 \\
\hline $\mathrm{SO}_{2 \text { lag4MA }}$ & $1.66^{*}$ & {$[1.26,2.07]$} & 0.0000 & $1.20^{*}$ & {$[0.39,2.02]$} & 0.0037 \\
\hline $\mathrm{O}_{3}$ & -0.03 & {$[-0.07,0.01]$} & 0.1703 & $0.58^{*}$ & {$[0.50,0.66]$} & 0.0000 \\
\hline $\mathrm{O}_{3_{\text {lag2 }}}$ & $-0.13^{*}$ & {$[-0.17,-0.08]$} & 0.0000 & $0.12^{*}$ & {$[0.02,0.21]$} & 0.0163 \\
\hline $\mathrm{O}_{3_{\operatorname{lag} 4 M A}}$ & 0.05 & {$[-0.04,0.13]$} & 0.2520 & $-0.87^{*}$ & {$[-1.05,-0.69]$} & 0.0000 \\
\hline TDIF & $-0.17^{*}$ & {$[-0.21,-0.13]$} & 0.0000 & 0.01 & {$[-0.07,0.09]$} & 0.7789 \\
\hline TDIF $_{\text {lag1 }}$ & 0.03 & {$[0.00,0.07]$} & 0.0746 & $-0.08^{*}$ & {$[-0.16,0.00]$} & 0.0391 \\
\hline $\mathrm{TDIF}_{\text {lag4MA }}$ & $0.67^{*}$ & {$[0.59,0.75]$} & 0.0000 & $1.03^{*}$ & {$[0.87,1.19]$} & 0.0000 \\
\hline
\end{tabular}

* Significance level, $\mathrm{p}<0.05$

a Excess risk

For simple lag-2 day and lag-4 day moving average of $\mathrm{SO}_{2}$ concentration, a significant positive association with emergency admissions was seen, with strong lag and cumulative effects. The ER values of $\mathrm{SO}_{2_{\mathrm{lag} 2}}$ and $\mathrm{SO}_{2_{\mathrm{lag} 4 \mathrm{MA}}} n$ were $0.74 \%$ (95\% CI $0.29 \%$ to $1.20 \%$ ) and $1.20 \%$ (95\% CI $0.39 \%$ to $2.02 \%$ ), respectively. In contrast to the effects of PM2.5, the current-day and simple lag- 2 days of $\mathrm{O}_{3}$ concentration were significantly and positively associated with emergency admissions, with ERs $0.58 \%$ (95\% CI $0.50 \%$ to $0.66 \%$ ) and $0.12 \%$ ( $95 \% \mathrm{CI} 0.02 \%$ to $0.21 \%$ ), respectively. However, the cumulative effects of $\mathrm{O}_{3}$ were negatively associated with emergency admissions; the ER for lag4MA of $\mathrm{O}_{3}$ was $-0.87 \%$ ( $95 \%$ CI $-1.05 \%$ to $-0.69 \%)$. Temperature differences in $24 \mathrm{~h}$ also showed strong 
positive cumulative effects. The ER value for lag4MA of TDIF24H was 1.03\% (95\% CI $0.87 \%$ to $1.19 \%$ ) for every $1{ }^{\circ} \mathrm{C}$ increase.

\section{Discussion}

We analyzed the daily admission data of three pediatric tertiary hospitals in Shanghai from January 1, 2013 to November 30, 2014, together with local environmental data. During our research period, there were a total of about 10,000 outpatient admissions and 2000 emergency admissions per day in these three pediatric hospitals.

\section{Modes of calendar factors influence on hospital admissions}

According to our observations and analysis, the total admissions for these hospitals varied by year (Additional file 1: Fig. S4); however, admission volumes in these hospitals shared some common patterns. Generally, both outpatient and emergency admissions of these pediatric hospitals were highly affected by calendar factors, especially the day of the week (Additional file 1: Fig. S1), month of the year (Additional file 1: Fig. S2), public holidays, and school vacations (Additional file 1: Fig. S3); previous studies have confirmed this finding [21].

Monday is a busy day for both outpatient and emergency departments. However, since outpatient departments are closed on weekends and public holidays, patient traffic directs to the ER on such days. Thus, weekend and holidays these are busy days for emergency departments. Pediatric hospital admissions were higher in winter than in warmer seasons. However, outpatient and emergency departments had fewer admissions during winter vacations and during summer vacations. Winter vacations for children and the Chinese New Year public holiday week often occur in February and are associated with mass travel of Shanghai residents to their respective hometowns, which is associated with a reduced utilization of Shanghai hospital resources.

According to data from Hospital A, chronic disease-related outpatient departments had higher admissions during summer vacations (Fig. 2). For example, the departments of endocrinology, surgery, nephrology, neurology, and urology had more pediatric admissions during summer vacations. However, the infectious diseases department reached peak admissions in June (before summer vacations begin); daily admissions then dropped dramatically during summer vacation (Fig. 2).

We suspect that there are two feasible explanations for this phenomenon: (i) summer vacations resulted in fewer school-acquired infections; (ii) vacation travel reduced the child population in the city. When children are in school, they spend more time together indoors than when they are on vacation, which facilitates the spread of infectious pathogens. As a result, admissions for infectious diseases are higher when schools are in session. When children are home during their summer vacation, they spend less time indoors together and reduce the indoor transmission route of pathogens; thus, infectious disease admissions decline. However, additional information is needed before a final conclusion can be reached in this regard. For outpatients, we suspect that the marked increase in outpatient admissions during summer vacations can be explained by traveling patients such as children with chronic diseases from surrounding regions who 
arrive into Shanghai during their school vacations with the goal to receive better medical service.

\section{Modes of environmental conditions influence on hospital admissions}

We performed regression analysis to investigate the effect of short-term adverse environmental conditions on pediatric hospital admissions. We found that the concentration of air pollutants and difference in daily temperatures were positively associated with hospital admissions. According to our observations, the effect of $\mathrm{NO}_{2}$ was a $0.27 \%$ increase (95\% CI $0.23 \%$ to $0.32 \%$ ) in outpatient admissions and $0.78 \%$ increase (95\% CI $0.68 \%$ to $0.88 \%$ ) in emergency admissions. PM2.5 has been reported to have an important role in increasing morbidity and mortality because it can penetrate capillary vessels of the lungs and reach the alveoli. Extensive research has been conducted on the association between PM2.5 and respiratory diseases. Previous systematic reviews and meta-analyses have reported the effect of PM2.5 on hospital admissions for asthma was an ER of 2.3\% (95\% CI $1.5 \%$ to $3.1 \%$ ) and $2.5 \%$ (95\% CI $1.3 \%$ to $3.7 \%$ ) for children and adults, respectively [1]. However, unlike $\mathrm{NO}_{2}$, the concentrations of PM2.5 and $\mathrm{CO}$ in our study showed some multi-faceted effects on pediatric hospital admissions. The concentrations of PM2.5 and $\mathrm{CO}$ were significantly associated with decreased overall current-day outpatient admissions (Fig. 3) as well as admission for all three hospitals (Additional file 1: Fig. S5). However, PM2.5 and CO were also significantly associated with increased current-day emergency admissions at all three hospitals. We suspect that if air quality worsens, fewer people are willing to go outdoors, including people with non-acute illnesses. Indeed, this hypothesis could also explain the negative associations of $P R C P$ (the amount of rainfall) with patient admissions. PM2.5 and CO levels largely reflect fossil fuel-related air pollution levels and are more closely associated with poor visibility than $\mathrm{NO}_{2}$. Despite the possibility that PM2.5 could result in fewer current-day outpatient admissions, PM2.5 eventually harms children's health. Compared with outpatient departments, the influence of air pollutants on emergency pediatric admissions was more apparent.

\section{Advantages and limitations}

A notable advantage of the present study is the representativeness of the pediatric admissions data. Through support from the HIE network of Shanghai, we included data from three pediatric hospitals for a total 10,000 outpatient and 2000 emergency admissions, covering over $75 \%$ of the total pediatric admissions of Shanghai during the study period. The main limitation of this study is the high degree of heterogeneity of the hospital admission data, because the data collected from the HIE network were not well organized into different clinical departments. Thus, we did not analyze the associations between environment measurements and admissions to clinical departments. Different clinical departments dealing with different diseases have different admission trends and different responses to adverse environmental conditions (Fig 2). Regression analysis for total hospital admissions was therefore missing many details of such associations. 


\section{Conclusions}

In summary, we conducted a retrospective study of daily hospital admission data from three regional tertiary pediatric hospitals in Shanghai. In this study, we investigated the effect of multiple calendar factors and environmental conditions on pediatric admissions. The results suggested that calendar factors and adverse environmental conditions have an important influence on pediatric admissions. Our work contributes to the limited knowledge of the factors influencing overall pediatric hospital admissions and can help to improve understanding of the short-term trends of pediatric admissions in a mega-city like Shanghai, and can be utilized to guide decisionmaking in pediatric hospital management and public health policy.

\section{Additional files}

Additional file 1. Additional figures.

Additional file 2. Additional table.

\section{Abbreviations}

TEP_MEAN: daily mean temperature; RHUM: daily mean relative humidity; TDIF24H: temperature difference in 24 h; MTD48H: absolute value of mean temperature difference in 48 h; PRCP: amount of precipitation; GAM: generalized additive model; $\mathrm{CO}$ : carbon monoxide; $\mathrm{NO}_{2}$ : nitrogen dioxide; $\mathrm{SO}_{2}$ : sulphur dioxide; $\mathrm{O}_{3}$ : ozone; $\mathrm{Cl}$ : confidence interval; PM10: fine particles 10 micrometers or less in diameter; PM2.5: fine particles 2.5 micrometers or less in diameter; HIE: health information exchange; WHO: World Health Organization; ER: excess risk.

\section{Authors' contributions}

GJY initiated this research project. GJY and WBC managed funding. GJY and HL designed this study. GJY, JLG, HL, and JPJ performed the experiments and conducted the statistical modeling. TL and WBC performed the data analysis. JLG, HL, GJY, JPJ, GZG, and WBC designed, wrote, and reviewed the manuscript. All authors read and approved the final manuscript.

\section{Author details}

1 Department of Children's Healthcare, Shanghai Children's Hospital, Shanghai Jiao Tong University, 355 Luding Road, Putuo District, Shanghai 200062, China. ${ }^{2}$ Department of Bioinformatics and Biostatistics, SJTU-Yale Joint Center for Biostatistics, School of Life Science and Biotechnology, Shanghai Jiao Tong University, Shanghai 200240, China. ${ }^{3}$ Shanghai Institute of Medical Genetics, Shanghai Children's Hospital, Shanghai Jiao Tong University, Shanghai 200062, China. ${ }^{4}$ Key Laboratory of Molecular Embryology, Ministry of Health \& Shanghai Key Laboratory of Embryo and Reproduction Engineering, Shanghai 200040, China. ${ }^{5}$ Bulgarian Institute of Genomics and Precision Medicine, Sofia, Bulgaria. ${ }^{6}$ Department of Bioengineering, Bioinformatics Program, University of Illinois at Chicago, Chicago, IL 60607, USA.

\section{Acknowledgements}

We would like to thank Prof. Zhang-sheng Yu from Shanghai Jiao Tong University and Prof. Shuang-ge Ma from Yale University for their valuable discussions. We would also like to thank Zhi-han Wei and Dr. Cong Liu from Shanghai Jiao Tong University and the University of Illinois at Chicago for their valuable input. We would like to thank Dr. Yi Hu from Shanghai Children's Hospital for her revisions of the manuscript, as well as Analisa Avila, ELS, of Edanz Group (http://www.edanz editing.com/ac) for editing a draft of this manuscript.

\section{Competing interests}

The authors declare that they have no competing interests.

\section{Availability of data and materials}

Data can be requested and obtained by contacting the corresponding author.

\section{Funding}

This work is supported by the National Key R\&D Program of China 2018YFC0910500, and Neil Shen's SJTU Medical Research Fund; Science and Technology Commission of Shanghai Municipality (STCSM) grant No. 17DZ22512000, Shanghai Municipal Commission of Health and Family Planning Grant No. 2018ZHYL0223, the New Hundred Talents Program of Shanghai Health System (No. XBR2013122), and Shanghai Jiaotong University School of Medicine Nos. TM201501, TM201612. Shanghai Municipal Commission of Health and Family Planning (No. 20144Y0179), and Shanghai Jiao Tong University Medical and Engineering Cooperation Fund (ZH2018QNA30).

\section{Ethics approval and consent to participate}

This study did not involve any individual participants, and no individual information was collected. 


\section{Publisher's Note}

Springer Nature remains neutral with regard to jurisdictional claims in published maps and institutional affiliations.

Received: 29 August 2018 Accepted: 16 January 2019

Published online: 08 February 2019

\section{References}

1. Zheng XY, Ding H, Jiang LN, Chen SW, Zheng JP, Qiu M, et al. Association between Air Pollutants and Asthma Emergency Room Visits and Hospital admissions in time series studies: a systematic review and meta-analysis. PLoS ONE. 2015;10(9):e0138146. https://doi.org/10.1371/journal.pone.0138146.

2. Sunyer J, Spix C, Quenel P, Ponce-de-Leon A, Ponka A, Barumandzadeh T, et al. Urban air pollution and emergency admissions for asthma in four European cities: the APHEA Project. Thorax. 1997;52(9):760-5.

3. Dehghan A, Khanjani N, Bahrampour A, Goudarzi G, Yunesian M. The relation between air pollution and respiratory deaths in Tehran, Iran- using generalized additive models. BMC Pulm Med. 2018;18(1):49. https://doi.org/10.1186/ s12890-018-0613-9.

4. Xu X, Ha SU, Basnet R. A review of epidemiological research on adverse neurological effects of exposure to ambient air pollution. Front Public Health. 2016;4:157. https://doi.org/10.3389/fpubh.2016.00157.

5. Hoek G, Krishnan RM, Beelen R, Peters A, Ostro B, Brunekreef B, et al. Long-term air pollution exposure and cardiorespiratory mortality: a review. Environ Health. 2013;12(1):43. https://doi.org/10.1186/1476-069X-12-43.

6. Olmo NR, Saldiva PH, Braga AL, Lin CA, Santos Ude P, Pereira LA. A review of low-level air pollution and adverse effects on human health: implications for epidemiological studies and public policy. Clinics (Sao Paulo). 2011;66(4):681-90.

7. Bell ML, Ebisu K, Peng RD, Walker J, Samet JM, Zeger SL, et al. Seasonal and regional short-term effects of fine particles on hospital admissions in 202 US counties, 1999-2005. Am J Epidemiol. 2008;168(11):1301-10. https://doi. org/10.1093/aje/kwn252.

8. Grimalt JO, Bose-O'Reilly S, van den Hazel P. Steps forward reduction of environmental impact on children's health Environ Res. 2018;164:184-5. https://doi.org/10.1016/j.envres.2018.02.015.

9. Suk WA, Ahanchian H, Asante KA, Carpenter DO, Diaz-Barriga F, Ha EH, et al. Environmental pollution: an underrecognized threat to children's health, especially in low- and middle-income Countries. Environ Health Perspect. 2016;124(3):A41-5. https://doi.org/10.1289/ehp.1510517.

10. Perera FP. Multiple threats to child health from fossil fuel combustion: impacts of air pollution and climate change. Environ Health Perspect. 2017;125(2):141-8. https://doi.org/10.1289/EHP299.

11. Barnett AG, Williams GM, Schwartz J, Neller AH, Best TL, Petroeschevsky AL, et al. Air pollution and child respiratory health: a case-crossover study in Australia and New Zealand. Am J Respir Crit Care Med. 2005;171(11):1272-8. https ://doi.org/10.1164/rccm.200411-15860C.

12. Huang R, Bian G, He T, Chen L, Xu G. Effects of meteorological parameters and PM10 on the incidence of hand, foot and mouth disease in children in China. Int J Environ Res Public Health. 2016. https://doi.org/10.3390/ijerph1305 0481.

13. Lim H, Kwon HJ, Lim JA, Choi JH, Ha M, Hwang SS, et al. Short-term Effect of Fine Particulate Matter on Children's Hospital Admissions and Emergency Department Visits for Asthma: a systematic review and meta-analysis. J Prev Med Public Health. 2016;49(4):205-19. https://doi.org/10.3961/jpmph.16.037.

14. Bono R, Romanazzi V, Bellisario V, Tassinari R, Trucco G, Urbino A, et al. Air pollution, aeroallergens and admissions to pediatric emergency room for respiratory reasons in Turin, northwestern Italy. BMC Public Health. 2016;16:722. https ://doi.org/10.1186/s12889-016-3376-3.

15. Rodriguez-Villamizar LA, Magico A, Osornio-Vargas A, Rowe BH. The effects of outdoor air pollution on the respiratory health of Canadian children: a systematic review of epidemiological studies. Can Respir J. 2015;22(5):282-92. https://doi.org/10.1155/2015/263427.

16. Zhou Y, Wang W, Pei Y, Zhao X, Chen Y, He X, et al. Analysis and reflections on pediatric bed allocation and utilization in Shanghai (Chinese). Chin Health Resour. 2014;17(1):4.

17. Hastie T, Tibshirani R. Generalized additive models for medical research. Stat Methods Med Res. 1995;4(3):187-96.

18. Sullivan KJ, Shadish WR, Steiner PM. An introduction to modeling longitudinal data with generalized additive models: applications to single-case designs. Psychol Methods. 2015;20(1):26-42. https://doi.org/10.1037/met0000020 -21923-001.

19. Kan H, London SJ, Chen G, Zhang Y, Song G, Zhao N, et al. Differentiating the effects of fine and coarse particles on daily mortality in Shanghai, China. Environ int. 2007;33(3):376-84. https://doi.org/10.1016/j.envint.2006.12.001.

20. Cleveland RB, Cleveland WS, MCRae JE, Terpenning I. STL: a seasonal-trend decomposition procedure based on loess (with discussion). J Off Stat. 1990;6:3-73.

21. Walker AS, Mason A, Quan TP, Fawcett NJ, Watkinson P, Llewelyn M, et al. Mortality risks associated with emergency admissions during weekends and public holidays: an analysis of electronic health records. Lancet. 2017:390(10089):62-72. https://doi.org/10.1016/S0140-6736(17)30782-1. 